Media Informatika, Vol. 6, No. 1, Juni 2008, 57-69

ISSN: 0854-4743

\title{
MINIMIZING THE PROBLEMS OF ENTERPRISE RESOURCE PLANNING (ERP) IMPLEMENTATION FOR SMALL TO MEDIUM CIGARETTE COMPANY THROUGH FRAMEWORK FOR APPLICATIONS OF SYSTEMS THINKING (FAST)
}

\author{
Muhammad Yasir Zain \\ e-Mail:yasir.zain@gmail.com
}

\begin{abstract}
This research is aimed to study the possibilities of implementing Enterprise Resource Planning (ERP) within Small to medium enterprises especially Cigarette Company through analysis, design systems and implementing phase. Since ERP system shows its power, lots of large company tried to implement ERP system within the company. In 2000, more than $60 \%$ of fortune 1000 companies were considering or had already implement at least one core of ERP module, even though it need huge capital to be invested. Lower scale of companies could not afford to implement the ERP system. The emerging Small to Medium Enterprise (SME) drove companies to more tight competition that force the companies to create more effective and efficient business process. Some of the companies tried to implement ERP systems through in-house development system. But they have to face failure since there are obstacles faced by the company such as less experience on developing systems. To fulfill the demand of ERP system, many vendors offer ready-to-use system for SME which sold in more affordable price or even free such as open source systems. The ready-to-use systems are quite easy to implement. Anyhow, problems might occur on the implementation process. FAST which stands for Framework for Application of Systems Thinking might help the company to reduce the problems that might occur on the implementation process since it has several steps as the problems filter.
\end{abstract}

Keywords: Enterprise Resource Planning (ERP), Analyzing and designing systems, Small to Medium Enterprise (SME), Framework for Applications of systems thinking (FAST), Cigarette Company

\section{BACKGROUND}

Rapid changes in Information Technology create numerous threats and challenges for businesses. Convergence between Information Technology and Communication technology which also very popular known as Information and Communication Technology (ICT) not just became a tool to conduct easier processes which had done manually before but those changes drove businesses into a new business battlefield. New business models emerge since ICT create new ways of companies doing their businesses. ICT also makes running a successful business more difficult than ever before. To achieve a successful business and competitive, middle to top level management must use technology to improve information flow, reduce costs, streamline business processes, offer product variety, establish linkage with suppliers, and to reduce response time to customer 
needs and expectations (Beheshti, 2006). Many organizations tried to transform their businesses in an effort to sense and respond more quickly to global threats and demands for cost cutting (Martin, 2002).

Digital working process is very popular new paradigm to improve businesses information service to its stakeholders which no longer use human physical knowledge, but have been changed by using digital knowledge. Along with the growth of information and communication technology, delivering value process to businesses' stakeholders shall no longer using officer's energy but have been done by using computer energy, thereby the existing human resource can be transferred to increase company's performance which requiring more human being idea.

Tight competition has been started in every industry, including in the cigarette and tobacco industry. Since the past few years ago, cigarette companies contribute substantially to the state revenues and absorb considerable quantities of manpower from the non-formal sector. Thousands of people work in tobacco and cigarette industry. According to Bali Post (2007), there are 3.961 cigarette companies in 2006 which produce 218.72 million sticks of cigarette.

In order to win the competition, cigarette companies should take profit and provide maximum customer value. Effective business process would affect on the goal that company would achieve and the whole process of doing businesses. That is why company should involve the whole part of the company including external entities and internal entities as well such as Human Resources Department, Accounting Department, Suppliers, Productions, Shareholders, and even external community around the company.

Top and middle level managements has great effects on achieving company's goal especially the IT person which should have more control and strategic of Information technology planning (Jogiyanto, 2005). In order to accomplish the job, IT executive should have hybrid knowledge which is consist of technical IT knowledge and business knowledge.

Table 1. Mild cigarette sales 2006

\begin{tabular}{|l|l|l|}
\hline \multicolumn{1}{|c|}{ Products } & \multicolumn{1}{c|}{ Company } & \multicolumn{1}{c|}{ Number of sales } \\
\hline A Mild & PT HM Sampoerna & 11.1 \\
\hline Clas Mild & PT Nojorono & 3.5 \\
\hline Star Mild & PT. Bentoel & 0.75 \\
\hline LA Light & PT. Djarum & 0.825 \\
\hline X Mild & PT. Bentoel & 0.6 \\
\hline U Mild & PT HM Sampoerna & 0.33 \\
\hline Mezzo & PT. Djarum & 0.08 \\
\hline
\end{tabular}

Source: SWAsembada Magazine

Lots of Cigarette Company tried to change the way they do their business and tried to improve their business processes to face the changes on cigarette industry and is an effort to win the competition. There are still a lot of cigarette companies maintain their old business process with its obsolete sets of tools 
especially small and medium businesses. Some divisions or departments involved in the business process conduct their job individually and accomplish the job manually. Thus sometimes few business processes should be delayed due to the belated information and process flow.

Higher scale of Cigarette Company faces very tight competition. As shown by Table 1 which explain number of sales of Mild class cigarette produce by highest cigarette company in Indonesia.

The data depict the stiff competition between high scales of Cigarette Companies. The competition among lower scale company occurred on small and medium businesses which compete in a smaller battlefield with more competitors. There are several aspects that should be provided by Cigarette Company to capture the market, they are:

1. Product availability in every point of sales. Availability is very important to compete with other competitor since the products are very easy to substitute.

2. Competitive pricing strategy.

3. Customer satisfaction on the taste of the cigarette. This factor related to several aspects such as raw materials, inventory system, etc.

4. Get accurate data easily, timely information and provide proper interface of the complex natured business.

\section{THEORETICAL BACKGROUND}

\subsection{Systems Analysis}

Computerization is not just creating report or providing data using computer, but it also represents an effective and efficient data flow through computer systems which is stand alone or integrated systems. In advance, computer systems could give two possibilities, whether it will drive business into a success story or a failure record. To overcome problems that might occur in the future, computerized systems should be analyzed first.

Bentley and Whitten (2007) define system analysis as a problem solving technique that decompose a system into its component pieces for the purpose of studying how well those component parts work and interact to accomplish their purpose. It is a prerequisite to systems design, the specification of a new and improved system. Systems analysis definitions stated before were shifting from classical to more contemporary definition. Systems analysis is a term that collectively describes the analysis phases in the context of the full classic route for the Framework for the Application of Systems Thinking (FAST) methodology which consists of eight steps. The first fifth steps is belongs to systems analysis, while the next steps are belong to design phase.

To obtain more understanding on FAST, we should understand the general systems development process and other systems development offered around the globe.

\subsection{Systems development Process}

Systems development refers to a set of activities, methods, best practices, deliverables, and automated tools that stakeholder which consists of systems 
owners, systems users, systems designers, systems builders, systems analysts, external service, and the project manager use to develop and continuously improve information systems and software (Bentley and Whitten, 2007).

Many organizations have a formal system development process consisting of a standard set of process or steps they expect will be followed on any system development project. This process may vary for different organizations, but mostly they were following general problem-solving step which consist of:

1. Identify the problems

2. Analyze and understand the problems

3. Identify solution requirement and expectation

4. Identify alternative solutions and choose the best course of action

5. Design the chosen solution

6. Implement the chosen solution

7. Evaluate the result. If the problem is not solved, return to step 1 or 2 as appropriate.

Information systems are complex product which consists of data, process, and communication building blocks and technologies that must serve the needs of variety of stakeholders. That is why company has no choice but to adopt and should follow standardized process to develop information systems in order to avoid failure on the next period.

System development process which also called systems development methodology is a formalized approach to the systems development process that includes the activities, methods, best practices, deliverables, and automated tools to be used for information systems development. Mostly, the systems development processes are derived from a natural systems life cycle event though sometimes those both terminologies incorrectly interchanged.

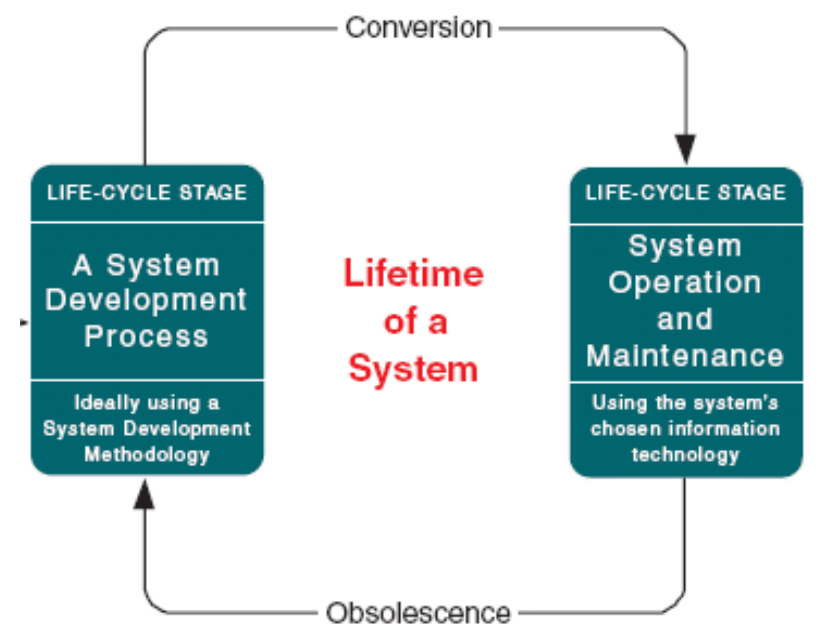

Figure 1 . The system life cycle Source: Bentley and Whitten (2007) 
There are two key events that trigger a change from one stage to the other as shown by figure 1 . The first trigger is when a system cycles from development and maintenance, a conversion must be conducted. The second trigger is when a system becomes obsolete, the cycle moved from system operation and maintenance to redevelopment process.

In fact, it is possible if a system may be in more than one stage at the same time. For instance, one version of software or system is in operation and maintenance, while the next version is in developing process which is in development process stage.

Bentley and Whitten (2007) explained that a system development methodology carried out the systems development stage of the systems lifecycle which also means that every single of information has its own life cycle. As described before, the methodology is the standard process to build and maintain that system and all other information systems through their life cycles.

There are many well known commercial methodologies such as Rapid Application Development (RAD), Architected Rapid Application Development (Architected RAD), Extreme Programming (XP), Information engineering (IE), Joint Application Development (JAD), and many more systems development methodologies offered by vendors around the world. Even though the methodology can be developed inside the company, commercial vendors realized that there are so many companies could not afford to build the methodology by itself since it has limitation especially on inappropriate dedicate staff.

Other methodology developed by Lonnie D. Bentley and Jeffery L. Whitten which also called FAST is a combination of many commercial and reference methodologies.

\subsection{The Framework for the Application of Systems Thinking (FAST) \\ Methodology}

FAST the acronym that stands for Framework for the Application of Systems Thinking is standard process or methodology used to develop and maintain information systems. It attempts to deliver the best possible information system quality in reasonable amount of time. This methodology also called agile method since its ability to support not only rapid application development, but also support other techniques including structured system analysis, information engineering, and object-oriented analysis and design as well.

Other characteristics of this methodology are flexible that gives developer ability to choose the best development strategy for each given project, it even support the option of purchasing information systems instead of building the systems in-house.

FAST methodologies consist of eight phases, even though the number of phases will vary from one methodology to another. Each phase produces deliverables that are passed to the next phase and documentation accumulated as completed on each phase. Figure 2, shows us the phase of classic FAST methodology. 


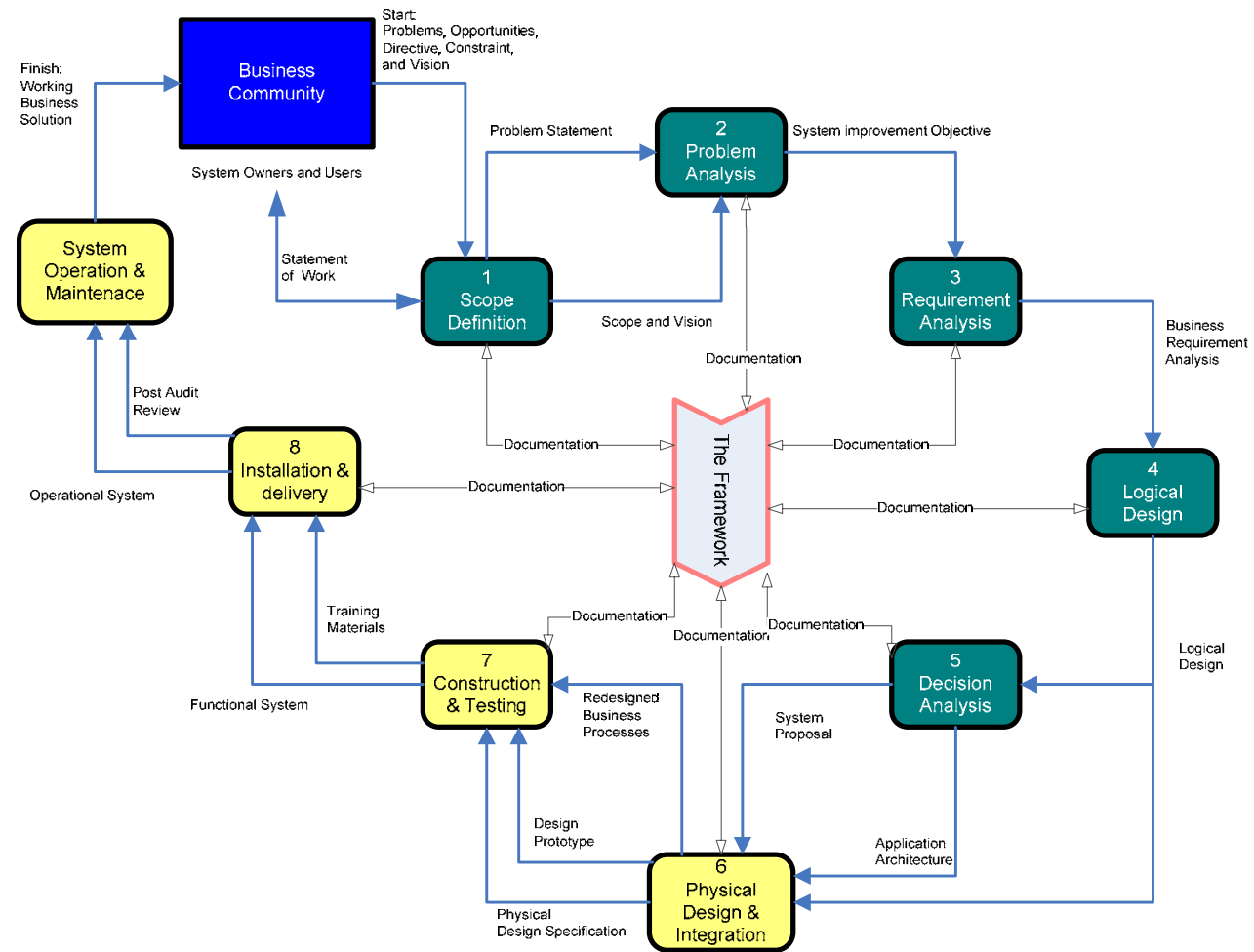

Figure 2. FAST Methodology

Source: Bentley and Whitten (2007)

\section{FINDINGS AND DISCUSSION}

Author divides this chapter into three main parts which is systems analysis, system design, and implementation.

\subsection{Systems Analysis}

\subsubsection{The Project Scope}

The first step of this system analysis is Scope definition phase. This phase has two aims which are to measure the worthiness of the project by defining the scope of the project; beside perceive problems, directives, and opportunities that triggered the project. After measuring the worthiness of the project, then moved to the next aim which creates plan to complete those project deemed worth through establishing the size of the project and its boundaries, and any other aspects such as project vision, any constraints or limitations, required project participants, and also budgeting.

The scope definition phase is triggered by combination of problems, opportunity, and directive. In advance, Bentley and Whitten (2007) add constraints, and vision as the trigger. Although this phase triggered by problems, opportunities, and directives, the goal of this phase is not to solve it, but only to catalog and categorize. 
Request for information system service as the prerequisite of identifying baseline problems and opportunities which are the first step on this phase stated that the company expects computerized information systems that could handle several important things such as:

- Integrate information flow among departments.

- Improve employees' performance through better personnel information systems

- Traceable incoming and out coming goods as well as the goods availability at warehouse, and faster goods delivery to the customer through manageable

- $\quad$ Faster inventory stocking procedures.

The baseline problems and opportunities recorded on problem statement matrix that identified through Wetherbe's PIECES framework (Bentley and Whitten, 2007) that covers Performances, Information (Data), Economics, Control (and security), Efficiency, and Service.

\subsubsection{Problem Analysis}

The previous phase already shown the problem statements, but it is not quite enough to understand the problems itself. Understanding the problem domain in order to thoroughly analyze its problems, opportunities and constraints were needed.

There are always current systems applied within the company whether it is performed manually or computerized which is use information technology. This phase studies the existing systems and analyzes the findings to provide the project team with a more thorough understanding of the problems that triggered the project.

Learning the current systems would help to understand the problems listed on the preliminary phase which sometimes might be only symptoms of other problems. Cause and effect analysis leads to true understanding of problems and can lead to more creative and valuable solutions.

\subsubsection{Requirement Analysis}

The requirement analysis needed to analyze the systems requires by the business which also include systems capabilities that provided for the users, types of data that must be captured, also interface and process that might be included in the systems as well.

The initial task of this requirement analysis is to identify and express requirements that translate the business improvement objective into an outline of functional and nonfunctional requirements.

While the functional requirements expresses by using use case modeling which also depict as a system context diagram as shown by Figure 3. This business requirement use case model which is examine how the users will uses the systems and also captures how the real work interact with the systems. 


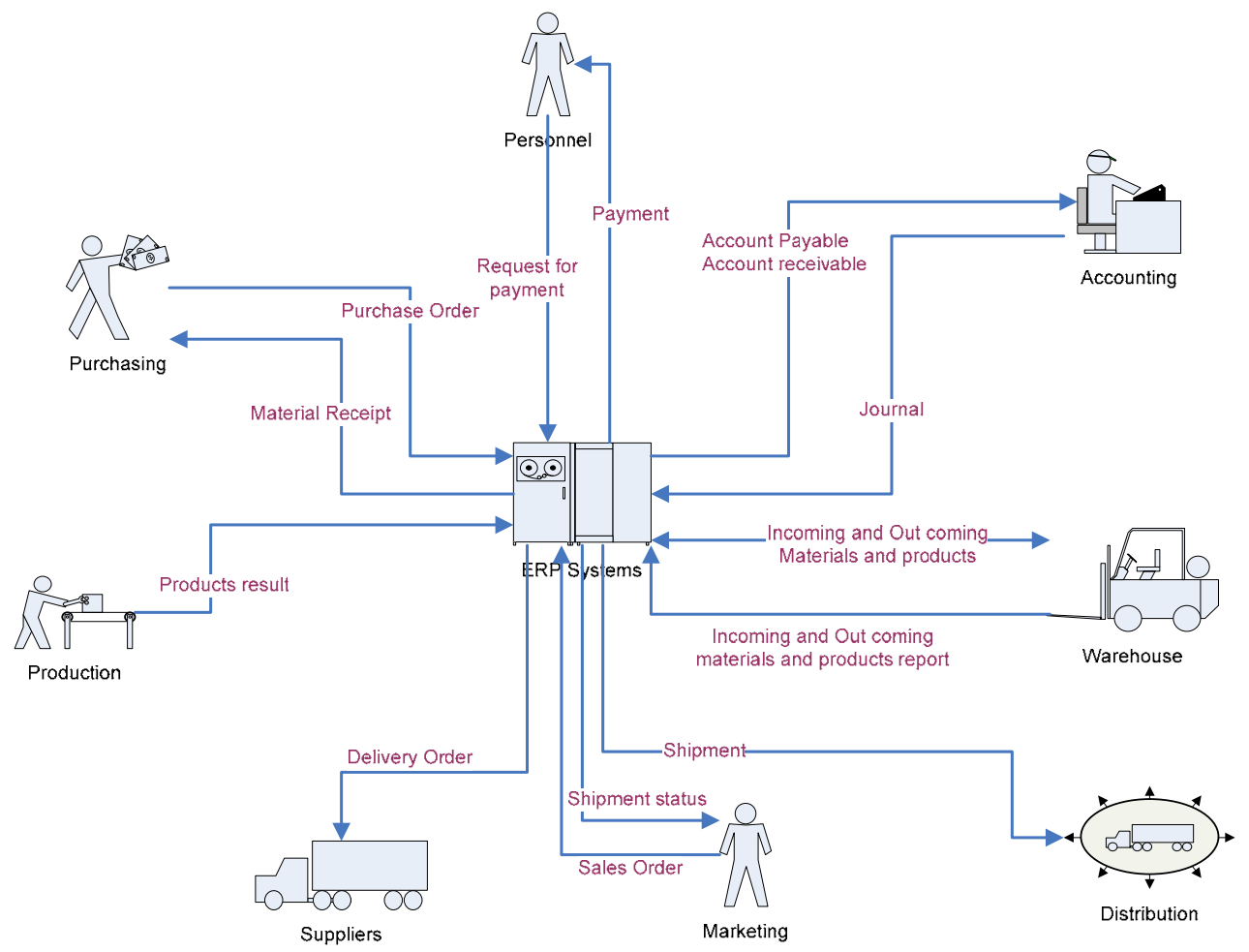

Figure 3. Cigarette Company systems context diagram Source: primary data

\subsubsection{Decision Analysis}

Decision analysis phase has a go or no-go decision node; that is why on this phase the project also has to face the judgment act. There are many reasons that the project decided to go such as the result of feasibility analysis.

The ERP systems could be acquired through several ways, those are inhouse development application, acquire of-the-shelf application whether it is commercial or open source application. In order to seize more effective capturing, organizing, and comparing the characteristics of different candidate solution, a candidate system matrix created by Bentley and Whitten (2007).

\subsection{Systems Design}

Starprise as the derivative of ADempiere which also derivative of Compiere uses the same combination of 2-tier and 3-tier architecture (Herzog, 2006) as shown by Figure 4 . The architecture consists of client tier, application tier, and database tier.

Database tier uses PostgreSQL or Oracle 10g so that it gives choices for its systems users. While for the application tier it uses JBOSS J2EE container that is open source systems. JBOSS is a well known application server which support Java Enterprise platform (J2EE). For the last tier compiere uses two types of applications, those are fat Java Client (Java Webstart) and web browser. 


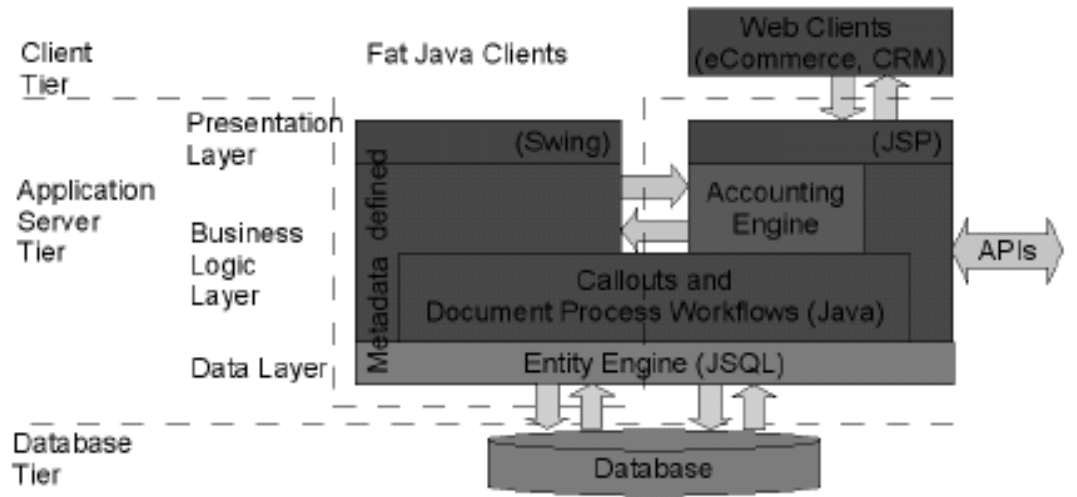

Figure 4. Compiere architecture.

Source: Herzog (2006).

Compiere provides three types of workflow (www.agenda.si):

- General Workflow which provides guidance and step-by-step instructions for achieving a task. For instance: Setup Wizards or Month End procedures. A user starts them from the menu.

- Document Process Workflow which started when processing any document. Users would extend these workflow types for approval situations. For instance: Special approval for orders over a certain amount.

- Document Value Workflow which is automatically started when any entity fulfils a user defined condition. For instance: Start credit approval for a new Business Partner.

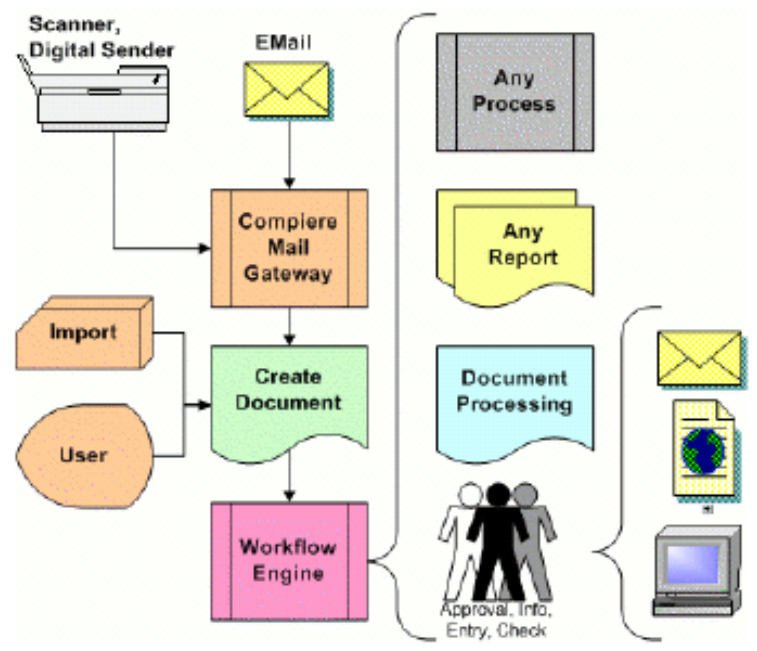

Figure 5. compiere work flow

Source: www.agenda.si 
All of the processes performed under client-server connection method. The client-server connection process between client, application server, and database server are shown by Figure 5. Local Area Network (LAN) were used to connect those third tier that enables workstation and server interconnected into a computer network so that they are able to communicate, exchange information and share resources. Each workstation connected to the server using UTP cable, while wireless device to connect too-far-away separated location.

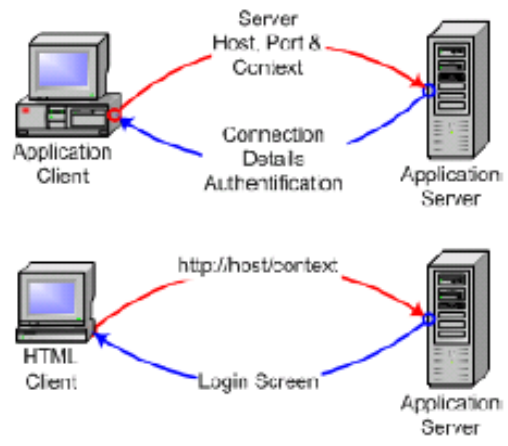

Figure 6. connection process of Compiere's architecture Source: www.agenda.si

\subsection{Implementation}

\subsubsection{Local Area Network}

To implement the new ERP system within small to medium cigarette company, understanding the physical area is a preliminary need. This condition intended to smooth the implementation process.

There are four main departments involved on this project, they are Production department, personnel department, accounting department, and sales department that usually separated into several different area.

\subsubsection{Starprise ERP Installation}

Starprise installation which consists of several steps is easier than commercial ERP systems. Since Starprise is the brand for adempiere which uses Bahasa on it interface, it fully supports by the adempiere's community or compiere's community since it also use the core of compiere as it programming base.

Starprise or adempiere can works on any operating system such as MS Windows, Linux, Sun Solaris, and Unix. While Oracle and PostgreSQL supports Adempiere as its database, it would be more database supported on the next period since compiere as adempiere's core already support more databases such as DaffodilDB, SyBase SQL, and any other databases.

There are six main steps to install Adempiere as shown by Figure 7 which consist installing java, database, setup Adempiere, creating database, and finishing the installation process. 
1. Install Java

\section{Java SDK}

\section{Install Database}

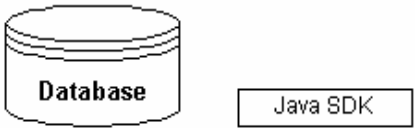

3. Download ADempiere unzip / tar

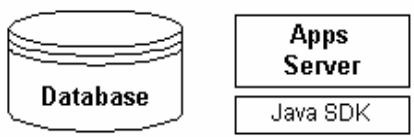

4. Setup ADempiere
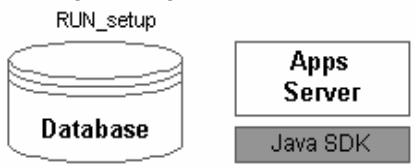

5. Create ADempiere DB

RUN_ImportAdempiere

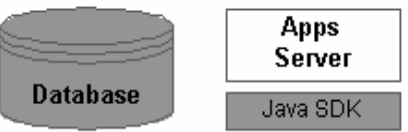

6. Complete Server Setup RUN_Server2

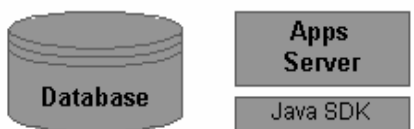

Figure 7. Adempiere Installation process Source: www.Adempiere.com

\section{CONCLUSION AND RECOMMENDATIONS}

\subsection{Conclusion}

The problem, how to analyze and design ERP implementation in small to medium scale Cigarette Company in Indonesia are exposed in the system analysis and system design. The scope of this research is in small to medium cigarette company in Indonesia only. So the conclusion might not be the same if research object changed.

From the research that has been conducted, it can be seen that there are several facts that should be considered by Cigarette Company and other parties who wants to implement ERP systems, those are: 
1. Problem faced by some cigarette company were lack goods information on inventory, less maximum workers' performance, disintegrated systems among departments, and obsolete systems and computer device. Those problems results on other crucial problems occurred.

2. ERP could integrate data and even business process that previously disintegrated. Therefore, it would solve problems occurred such as time consumes to get inventory status.

3. There are several choices to implement ERP system within the company whether it is in-house development, or acquire existing system offered on the market.

4. The ERP system that fits small to medium cigarette company is open source systems such as Starprise ADempiere.

5. FAST methodology could minimize the failure of implementation since it has several steps to analyze problems and implementation process.

6. The failure of ERP systems implementation could be minimized by studying the possible problems that might occurs from the previous research.

7. The most important thing is the power of ERP could be tasted by every type of company, whether it is large, medium, or even small company.

\subsection{Recommendation}

Regarding to findings and conclusion of this research, author recommends several points:

1. Small to medium cigarette company needs to convince its employees about the important of Information Technology for the company to minimize the resistance to change effect.

2. The rapid changing of information and communication technology and its penetration should considered by the company as its tool in order to increase the company's performance as a whole.

\section{REFERENCES}

Beheshti, Hooshang M. (2006). What managers should know about ERP/ERP II, College of Business and Economics, Radford University,Radford, Virginia, USA.

Bentley, Lonney D., and Whitten, Jeffrey L. (2007). System Analysis \& Design for the Global Enterprise, seventh edition, McGraw Hill.

Herzog, Thomas. (2006). A Comparison of Open Source ERP Systems, Universität Wien.

Hong, Kyung-Kwon, and Kim, Young-Gul. (2002). The critical success factor for ERP Implementation: an organizational fit Perspective, Information \& Management - Elsevier Science B. V.

Jogiyanto, H. M. (2004). Sistem Teknologi Informasi, pendekatan terintegrasi: konsep dasar, teknologi, aplikasi, pengembangan dan pengelolaan, Edisi II, penerbit ANDI, Yogyakarta.

Martin E, Wainright., Brown V. Carol., DeHayes W. Daniel., Hoffer A. Jeffrey., and Perkins C. William. (2005). Managing Information Technology, Prentice Hall. 
O'Donnell, Sean W. (2007). 5 Steps To Successful ERP Implementation, datacor.inc

Smyth, Robert W. (2001). Challenges to Successful Erp Use, The 9th European Conference on Information Systems, Slovenia.

Swa sembada magazine. (2006). No.13/XXII/29, Jakarta.

Wieder, Bernhard; Booth, Peter; Matolcsy, Zoltan P., and Ossimitz, Maria-Luise. (2006). The impact of ERP systems on firm and business process performance, Journal of Enterprise Information Management.

Wu, Jen-Her, and Wang, Yu-Min. (2006). Measuring ERP success: the ultimate users' view, International Journal of Operations \& Production Management.

http://www.bps.go.id

http://www.agenda.si/fileadmin/www.agenda.si/documents/Compiere.opis.pdf [accessed: September 8, 2007]

http://www.balipost.co.id/balipostcetak/2007/4/7/e6.htm [accessed: May 3, 2007]

http://www.destinationcrm.com/articles/default.asp?ArticleID=6162 [accessed: August 7, 2007] 